\title{
P09-08. The complexity of the infecting inoculum determines the outcome of infection
}

\author{
L Loh $^{2}$, J Reece ${ }^{2}$, J Petravic ${ }^{1}$, R Center ${ }^{2}$, M Davenport ${ }^{1}$ and SJ Kent*2
}

Address: ${ }^{1}$ University of NSW, Sydney, Australia and ${ }^{2}$ University of Melbourne, Parkville, Australia

* Corresponding author

from AIDS Vaccine 2009

Paris, France. 19-22 October 2009

Published: 22 October 2009

Retrovirology 2009, 6(Suppl 3):PI2I doi:I0.I I86/I742-4690-6-S3-PI2I

This abstract is available from: http://www.retrovirology.com/content/6/S3/PI2 I

(C) 2009 Loh et al; licensee BioMed Central Ltd.

\section{Background}

Many infected subjects acquire 2 or more strains of HIV-1, in some cases both CTL escape-mutants (EM) and wildtype (WT) variants. Eventual reversion to WT reflects fitter WT virus in vivo. However, reported reversion rates vary widely. Understanding reversion (and how to maintain unfit EM variants) should facilitate better approaches to HIV-1 control. We hypothesised that co-transmission of WT virus in the infecting inoculum leads to rapid reversion and more pathogenic infections.

\section{Methods}

A quantitative RT-PCR simultaneously measures WT and EM viral loads at the Mane-A*10-restricted SIV Gag KP9164-172 CTL epitope in pigtail macaques. Reversion of the K165R EM viruses from 5 SIV and SHIV inocula were assessed in 15 naïve $\mathrm{A}^{*} 10$-ve macaques.

\section{Results}

Infection with isolates containing $\geq 10 \%$ WT SIVmac239, SHIVmn229 or SHIVSF162P3 all show rapid growth of both WT and EM virus during acute infection and EM virus decays rapidly thereafter. Conversely, delayed reversion occurs in animals infected with a SIVmac239 K165R clone, and $\leq 4 \%$ WT SHIVs. Further, the reversion rate is proportional to target CD4 T cell number. Importantly, EM inocula with delayed reversion are less pathogenic, showing reduced peak and set point viral load compared to those infected with $\geq 10 \%$ WT in the inocula and showing rapid reversion ( $\mathrm{P}=0.0094, \mathrm{P}=0.0072$ respectively).

\section{Conclusion}

When infected with 2 viruses (both EM and >10\%WT), rapid outgrowth of WT virus occurs during acute infection. Delayed reversion to WT results if only EM virus initiates the infection, primarily due to some target cell depletion by the EM virus during acute infection prior to the appearance of WT virus. The delay in reversion, where acute viremia is primarily the less fit EM virus, results in a significant reduction in VL and will delay disease. This has implications for vaccine strategies to maintain weaker EM viruses in new hosts. 